\title{
Effect of structural parameters of high-pressure water jet nozzles on flow field features
}

\author{
Yilei Liu ${ }^{1,2^{*}}$, Hongqing Zhu', Suguo Huang ${ }^{2}$ \\ ${ }^{1}$ College of Resources \& Safety Engineering, China University of Mining \& Technology, Beijing \\ 100083, China \\ ${ }^{2}$ School of Mining Engineering, Guizhou University of Engineering Science, Bijie 551700, China
}

Email:380172207@qq.com

\begin{abstract}
This paper aims to disclose the exact effect of various nozzle structures on flow field features. For this purpose, the flow field variation of high-pressure (HP) water jet inside/outside the nozzle was simulated by the Fluent software. Then, the geometric parameters of the nozzle that might affect the water jet were numerically simulated, and the water jet speed distributions at all sections perpendicular to the nozzle axis were observed in details. The results show the water jet speed was basically the same at different distances from the nozzle axis; to maintain the same speed, the section length grew shorter the farther away from the axis. In addition, the author also derived the mathematical model for the effect of nozzle structure on outlet speed of the water jet. The research sheds new light on the flow field features of high-pressure water jet nozzles.
\end{abstract}

Keywords: High-Pressure (HP) Water Jet, Nozzle Structure, Flow Field Features, Numerical Simulation.

\section{INTRODUCTION}

In many low-permeability coal seams, it is impossible to implement the pressure relief of the protective layer mining. Fortunately, engineering practices have proven the effect of high-pressure (HP) water jet in hydraulic measures like punching, kerf cutting and fracturing. The HP water jet can overcome the "bottleneck effect" around the borehole, forming a vast fractured network [1-3]. The fractures will increase the permeability of the coal seam and change the distribution of coal stress and gas pressure. In addition, the coal body will be moistened and the initial emission speed of gas will be slowed down. Compared with other techniques, the hydraulic measures based on the HP water jet perform excellently in enhancing permeability and preventing outburst [4-7].

Owing to the regional difference in geologic structure and gas state, the specific technical parameters of the HP water jet must be determined before hydraulic permeability enhancement $[8,9]$. One of the key parameters is the effect of nozzle structure on the flow field features of the HP water jet. Unlike the traditional experimental approaches, the Fluent software can accurately simulate the features of flow field, and visualize the flow state of the HP water jet. Therefore, the software was adopted for this research, aiming to disclose the exact effect of various nozzle structures on flow field features $[10,11]$.

\section{FLOW FIELD MODEL OF HP WATER JET}

\subsection{Mathematical model of nozzle jet flow}

The flow state analysis of the HP water jet shows that the water jet is in hyper turbulent motion after exiting the nozzle, and is fit in with the basic parameters of the free jet of viscous fluid. Therefore, the flow state can be solved by the k- $\varepsilon$ model. The dissipation rate of the turbulent kinetic energy (TKE) $\varepsilon$ can be expressed as:

$\varepsilon=\frac{\mu}{\rho}\left(\frac{\partial u_{i}^{\prime}}{\partial x_{k}}\right)\left(\frac{\partial u_{i}^{\prime}}{\partial x_{k}}\right)$

The flow viscosity $\mu_{t}$ can be calculated by $\mu_{t}=\rho \cdot C_{\mu} \frac{k^{2}}{\varepsilon}$, where $C_{\mu}$ is a constant.

The corresponding transport equation of $\mathrm{k}-\varepsilon$ model is:

$$
\begin{aligned}
\frac{\partial(\rho k)}{\partial t}+\frac{\partial\left(\rho k u_{i}\right)}{\partial x_{i}}= & \frac{\partial}{\partial x_{j}}\left[\left(\mu+\frac{u_{i}}{\partial_{k}}\right) \frac{\partial k}{\partial x_{j}}\right]+ \\
& G_{k}+G_{b}-\rho \varepsilon-Y_{M}+S_{k}
\end{aligned}
$$




$$
\begin{aligned}
& \frac{\partial(\rho \varepsilon)}{\partial t}+\frac{\partial\left(\rho \varepsilon u_{i}\right)}{\partial x_{i}}= \\
& \frac{\partial}{\partial x_{j}}\left[\left(\mu+\frac{u_{i}}{\partial_{\varepsilon}}\right) \frac{\partial \varepsilon}{\partial x_{j}}\right]+ \\
& G_{1 \varepsilon} \frac{\varepsilon}{k}\left(G_{k}+C_{3 \varepsilon} G_{b}\right)-C_{2 \varepsilon} \rho \frac{\varepsilon^{2}}{k}+S_{\varepsilon}
\end{aligned}
$$

where

$$
G_{k}=\mu_{t}\left(\frac{\partial u_{i}}{\partial x_{j}}+\frac{\partial u_{j}}{\partial x_{i}}\right) \frac{\partial u_{i}}{\partial x_{j}}
$$

For an incompressible fluid, $G_{b}=0$; for a compressible fluid, $G_{b}=\rho g_{i} \frac{\mu_{t}}{P r_{t}} \frac{\partial T}{\partial x_{i}}$, where $\beta$ is the coefficient of thermal expansion $\rho=-\frac{1}{\rho} \frac{\partial \rho}{\partial T}$. For an incompressible fluid $Y_{M}=0$; for a compressible fluid, $Y_{M}=2 \rho \varepsilon M_{\mathrm{t}}^{2}$, where $M_{t}=\sqrt{k / a^{2}}$.

\subsection{Determination of physical model}

In light of the computer hardware, the flow fields inside and outside the HP water jet nozzle were numerically simulated in Fluent. The results on the external flow field show that the removal effect mainly relies on the pressure, and reaches the optimal status at the impact angle of $30^{\circ}$. The results on the internal flow field show that the internal flow speed distribution mainly rests on the inner conical surface; the water speed and nozzle intactness are relatively good at the cone angle of $15^{\circ}$; the best performance belongs to the nozzle with an inlet diameter of $1.5 \mathrm{~mm}$ and a length/diameter ratio of 2.5 .

In reference to the previous research findings, the model parameters were determined as: the contraction angle is $13^{\circ}$, the contraction section is $5 \mathrm{~mm}$ long, the straight tube is $12 \mathrm{~mm}$ long, and the straight tube is $3 \mathrm{~mm}$ in diameter [12-17]. The model was meshed into quadrilateral grids, the submerged water jet was adopted to cope with the effect of coal wall reflection on the water jet during the punching and kerf cutting (Figure 1).

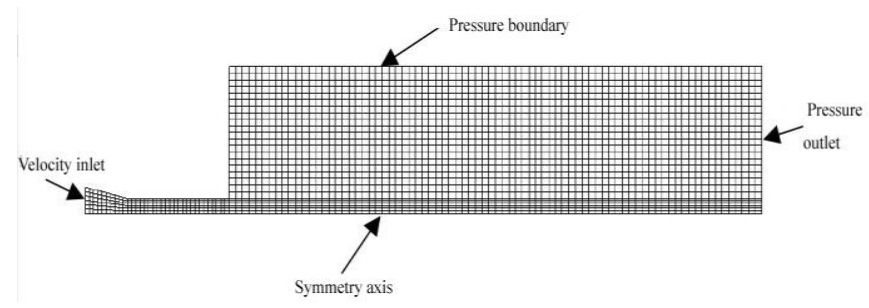

Figure 1. Submerged water jet model

\section{NUMERICAL SIMULATION AND RESULTS ANALYSIS}

\subsection{Effect of contraction angle on flow field}

The contraction angle of the water jet directly bears on the flow field, especially the outlet speed of the water jet. For timeliness, three different contraction angles were selected, namely $13^{\circ}, 30^{\circ}$ and $60^{\circ}$. The speed contours of these angles are respectively illustrated in Figures 2, 3 and 4.

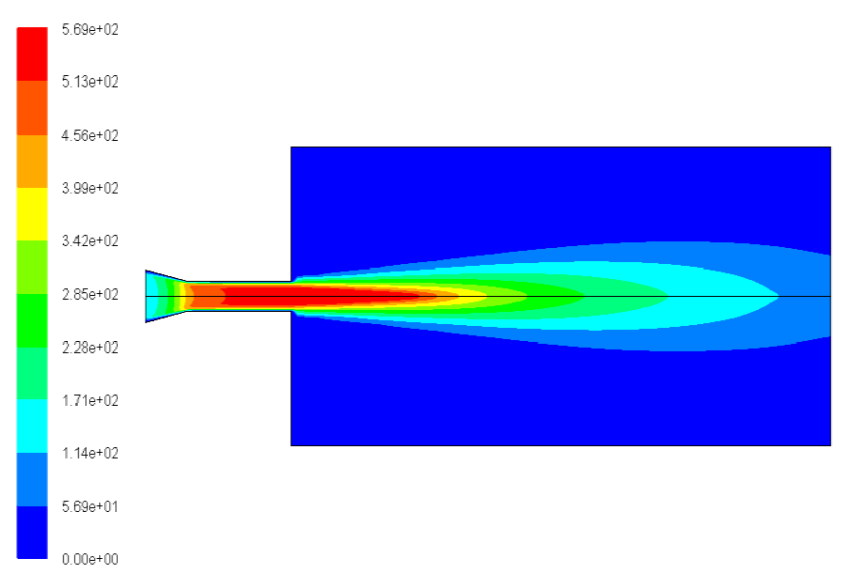

Figure 2. Water jet speed contour map at $13^{\circ}(\mathrm{m} / \mathrm{s})$

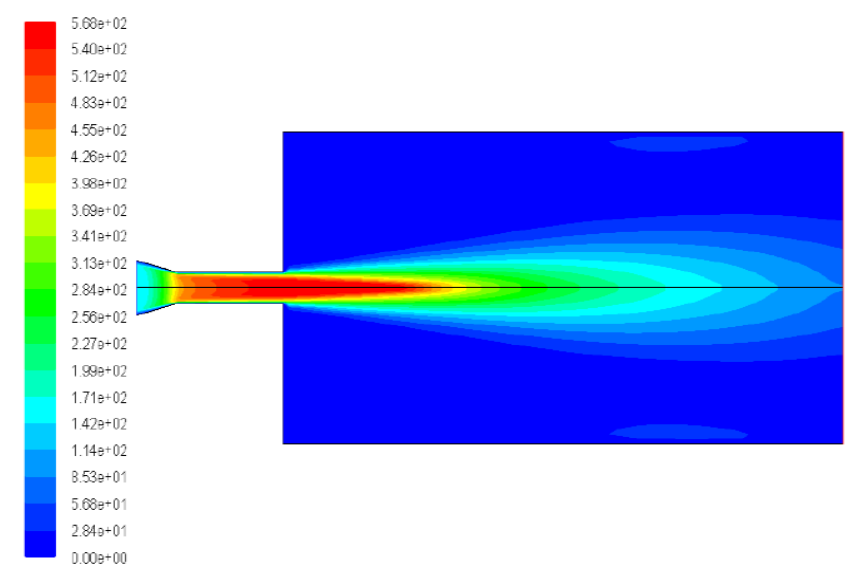

Figure 3. Water jet speed contour map at $30^{\circ}(\mathrm{m} / \mathrm{s})$
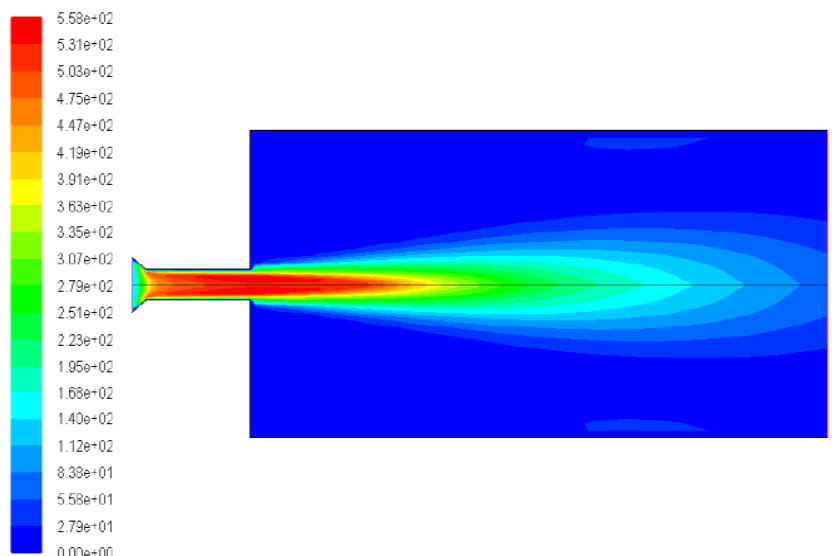

Figure 4. Water jet speed contour map at $60^{\circ}(\mathrm{m} / \mathrm{s})$

(1) Axial speed distribution of the water jet

The contour maps reveal that the three nozzles with different contraction angles differed slightly in the maximum speed. According to the theoretical formula, when the water pressure at the nozzle inlet $p_{i n}=20 \mathrm{MPa}$, the theoretical outlet speed of the water jet $v_{t}=200 \mathrm{~m} / \mathrm{s}$. In our simulation, the actual outlet speed of the water jet $v=187 \mathrm{~m} / \mathrm{s}$ at the contraction angle $\alpha=13^{\circ}$, that is, the speed coefficient $c_{v}=v / v_{t}=0.94 ; \nu=180 \mathrm{~m} / \mathrm{s}$ and $c_{v}=v / v_{t}=0.9$ at $\alpha=30^{\circ} ; v=170 \mathrm{~m} / \mathrm{s}$ and $c_{v}=v / v_{t}=0.89$ at $\alpha=60^{\circ}$. The simulated results agree well with the theoretical results. 
It can also be seen from the contour maps that the water jet picked up speed before it gradually slowed down after leaving the nozzle. In the contraction section, the water jet speed continued to increase at an ever-growing rate. The speed grew faster as the water jet approached the outlet. After entering the straight tube of the nozzle, the water jet was stabilized to a certain degree. There was a potential core region after the water jet left the nozzle. In this region, the water jet speed reached the maximum and remained constant. The water jet speed gradually decreased to 0 as it moved away from the potential core region. At the contraction angle of $13^{\circ}$, the water jet accelerated for a much longer time in the contraction section than at the other two angles. As the contraction angle $\alpha$ expanded to $30^{\circ}$ and $60^{\circ}$, the contraction section became shorter and shorter; So it is with the length of the acceleration section.

The length of the potential core region is a key indicator of water jet nozzle. It is found in our simulation that this region was the longest at $\alpha=13^{\circ}$; in this case, the water jet reached the fastest speed and the best degree of focus, leading to the maximum impact force. This conclusion is consistent with that of Ricci and Volcker: the nozzle produces the greatest impact pressure at the contraction angle $\alpha$ of $13^{\circ}$.

As shown in Figures $2 \sim 4$, for $\alpha=60^{\circ}$, the water jet lost much of its speed at the cone angle, and moved at varied speeds in the straight tube. The speed loss and imbalance affected the water jet speed. Hence, the maximum water jet speed in this case was slower than that at $\alpha=13^{\circ}$ and $30^{\circ}$. Overall, the $\alpha=60^{\circ}$ had a slower water jet speed than $\alpha=13^{\circ}$ and $30^{\circ}$ in both the straight tube and the potential core region. Moreover, in the potential core region, the dynamic pressure was slightly higher at $\alpha=13^{\circ}$ than at $\alpha=30^{\circ}$, and far greater than $\alpha=60^{\circ}$.

Considering the effect of contraction angle on water jet speed and dynamic pressure, $\alpha=30^{\circ}$ was deemed as the optimal contraction angle for the nozzle to maintain a fast outlet speed and a high dynamic pressure. Therefore, it is better to set the contraction angle of the nozzle at $13^{\circ}$ for coal cutting.

(2) Radial speed distribution of the water jet

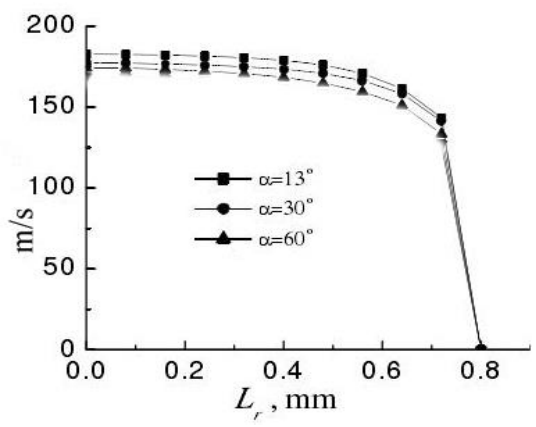

Figure 5. Effect of contraction angle on the distribution of outlet section speed

The relationship curves between the outlet speed and different contraction angles were plotted (Figure 5) to disclose the effect of contraction angle on the radial speed distribution of the water jet. As can be seen from Figure 5, the water jet moved the fastest at the axial center of the outlet section, thanks to the presence of the potential core region here. The farther it was from the axial center, the slower the water jet speed. The speed plunged to zero once the water jet reached the inner wall of the nozzle. It is clear that the contraction angle is negatively correlated with the outlet water jet speed. The contraction angles are ranked as $13^{\circ}>30^{\circ}>60^{\circ}$ in descending order of the outlet section speed. In addition, $\alpha=13^{\circ}$ and $\alpha=30^{\circ}$ shared similar speed distributions at the outlet section.

When the water jet was located at $L=5 d$ away from the nozzle exit, the relationship between the contraction angle and the section speed distribution was recorded in Figure 6. It can be seen that, in a section perpendicular to the water jet direction, the water jet speed increased as the water jet moved closer towards the axis of the nozzle. The trend is the same across all contraction angles. The speed remained basically the same at the points within the potential core region. By contrast, the speed dropped rapidly to 0 at the points outside the region. When $L_{r}<1.12 \mathrm{~mm}$, the water jet speed is negatively correlated with the contraction angle $\alpha$; when $L_{r}>1.12 \mathrm{~mm}$, the water jet speed is the slowest at $13^{\circ}$. In the latter case, however, the water jet was less scattered, and could exert a huge impact on coal.

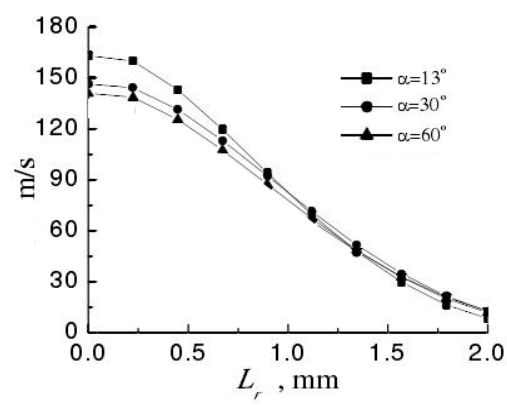

Figure 6. Water jet speed distribution at the section $L=5 d$ away from nozzle exit at different contraction angles

(3) Axial pressure distribution

The effect of different contraction angles on the axial pressure distribution of the flow field is shown in Figure 7. In the contraction section, the distribution of water jet pressure varied linearly; in the straight tube, the water jet pressure increased. According to the conservation of energy, the pressure energy of the water jet was converted into the kinetic energy in this section. As a result, the water jet was ejected from the nozzle at a high speed.

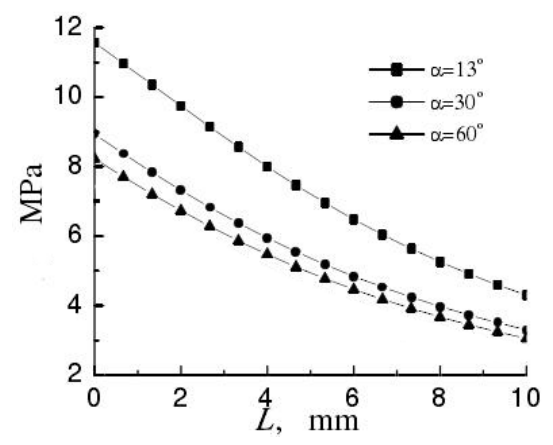

Figure 7. Effect of contraction angle on the pressure distribution along a section of the axis outside the nozzle

There was a potential core region at the axis of the nozzle. After the ejection, the nozzle was surrounded by an obvious low-pressure region. In the axial direction, the dynamic pressure of the water jet increased first and then decreased. This echoes our previous conclusion. Furthermore, the dynamic pressure peaked at the contraction section, and exhibited a declining trend after the water jet leaved the nozzle and with the increase in the contraction angle. Therefore, the 
water jet boasted the strongest dynamic pressure at $\alpha=13^{\circ}$, i.e. the greatest impact on the coal.

\subsection{Effect of different nozzle outlet diameters on flow field}

Without changing the other conditions, this section explores the variation in the flow field as the nozzle outlet diameter $\mathrm{d}$ shifts from $1.4 \mathrm{~mm}, 1.6 \mathrm{~mm}, 1.8 \mathrm{~mm}$ to $2.0 \mathrm{~mm}$, laying the basis for the selection of nozzle outlet diameter.

(1) Axial speed distribution

Figure 8 shows how different nozzle outlet diameters d affect the water jet speed along a section of the axis outside the nozzle. Since the nozzle outlet diameter was the only variable in the simulation, the axial speed of the nozzle became greater at the same distance from the nozzle when the nozzle diameter grew in size. Hence, the axial speed reached the maximum value at $\mathrm{d}=2.0 \mathrm{~mm}$. Owing to the large outlet diameter, the water jet at the outlet had a large diameter after being accelerated in the contraction section. In this case, the axial speed of the nozzle decreased rather slowly. In contrast, the axial speed of a small diameter nozzle dropped rapidly, leading to a great energy loss.

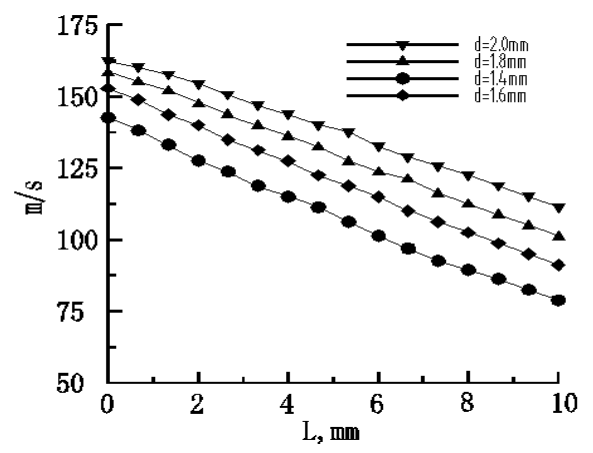

Figure 8. Effect of outlet diameter on the pressure distribution along a section of the axis outside the nozzle

\section{(2) Radial speed distribution}

Figure 9 displays the effect of different nozzle outlet diameters $d$ on the outlet section speed. It is clear that the water jet speeds were similar at all nozzle outlet diameters as long as the nozzle was close to the corresponding outlet section. When $L_{r}>0.5 \mathrm{~mm}$, the speed varied significantly at the outlet sections. For the nozzle with the outlet diameter of $2 \mathrm{~mm}$, the water jet speed attenuated relatively slowly, and the maximum jet speed exceeded that of the other three nozzles.

Figure 10 illustrates the relationship between the nozzle outlet diameter and the water jet speed at the section $L=5 \mathrm{~d}$ away from the nozzle exit. It can be seen that the axial water jet speed increased with the nozzle outlet diameter at the same distance $L=5 d$. With a fast outlet speed, the water jet passing through a large diameter nozzle tended to have a high energy. Thus, the larger the nozzle outlet diameter, the better coal cutting effect of the water jet.

(3) Axial pressure distribution

Figure 11 shows the relationship between nozzle outlet diameter and the axial pressure distribution at different distances from the axis. As can be seen from the figure, the axial pressure dropped as the water jet moved away from the axis for all nozzle outlet diameters. At the same distance from the axis, the axial pressure was almost linearly increasing with the growth in the outlet diameter.

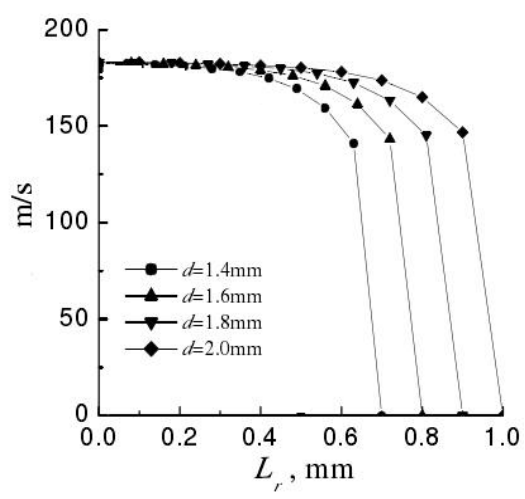

Figure 9. Effect of outlet diameter on the pressure distribution along a section of the axis outside the nozzle

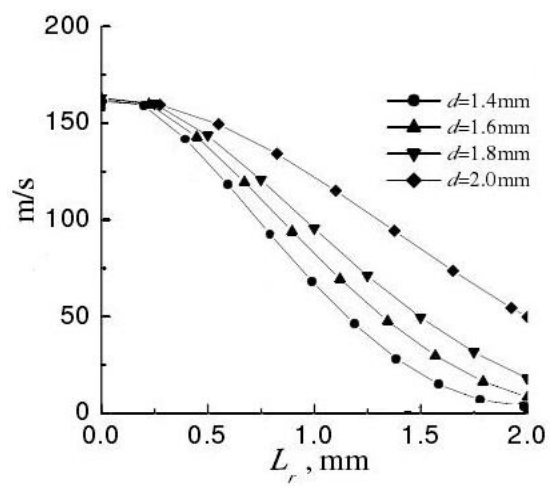

Figure 10. Effect of outlet diameter on speed distribution at the section $L=5 \mathrm{~d}$ away from the nozzle

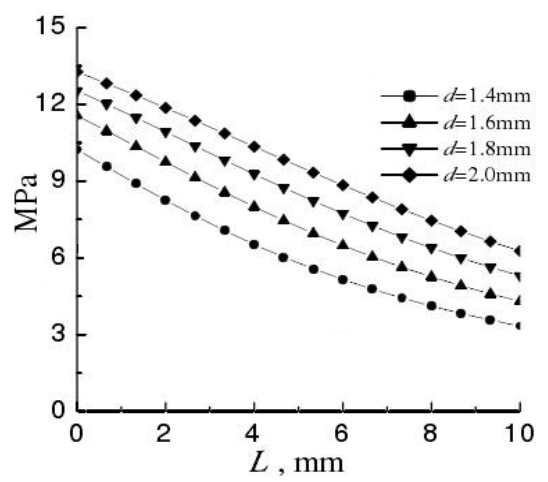

Figure 11. Effect of outlet diameter on axial pressure distribution

\subsection{Effect of straight tube length on flow field}

The length of the straight tube also has a great impact on the flow field of the water jet. Four models were established for numerical simulation. The variables include straight tube length (4mm (2D), 8mm (4D), $12 \mathrm{~mm}$ (6D) and 24mm(12D)), contraction angle $\left(13^{\circ}\right)$, contraction section length $(5 \mathrm{~mm})$, nozzle outlet diameter $(2 \mathrm{~mm})$. The grid model is similar to that depicted in Figure 1.

The relationship curve between axial jet speed, axial dynamic pressure and straight tube length are shown in Figures 12 and 13. Comparing the two figures, it is learned that the axial jet speed and the axial dynamic pressure varied in a similar pattern with the changes in the length of the straight tube: both parameters increased with the length and peaked at 
the length of $24 \mathrm{~mm}$. Whereas the potential core region is negatively correlated with the straight tube in length, the nozzle with a $4 \mathrm{~mm}$-long straight tube boasted the largest potential core region.

It may seem that the axial jet speed and axial dynamic pressure were the greatest at the straight tube length of 12D. However, the values are the maximum values in the straight tube. After the water jet left the nozzle, both the speed and dynamic pressure plunged rapidly. The largest potential core region belonged to the length of $2 \mathrm{D}$, but the speed and dynamic pressure were lower than those in other lengths.

To sum up, the optimal straight tube lengths are 4D and 6D, considering the balance between the length, speed and dynamic pressure.

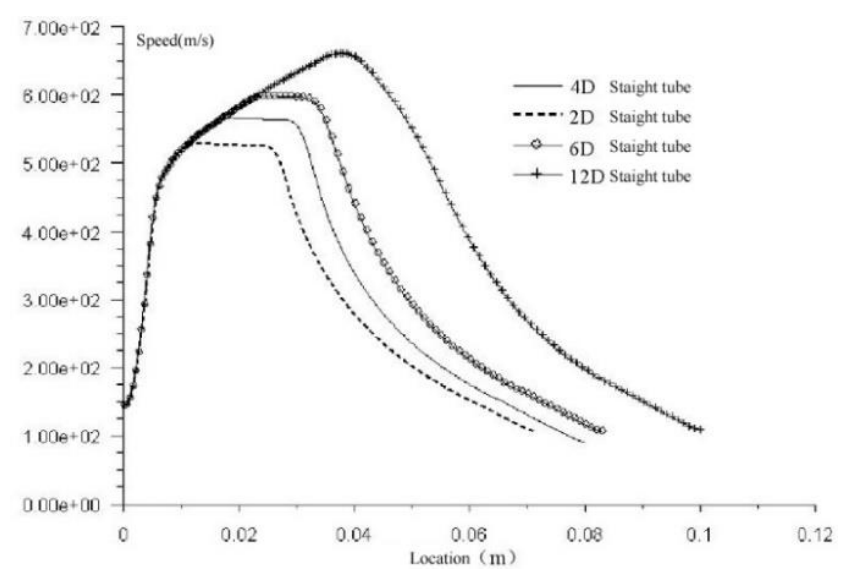

Figure 12. Water jet pressure along the axis at different straight tube lengths

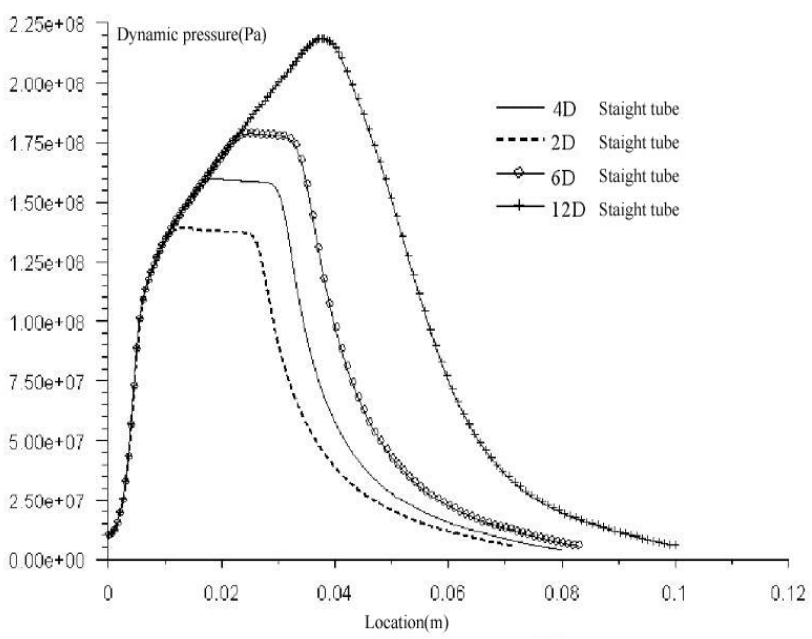

Figure 13. Water jet dynamic pressure along the axis at different straight tube lengths

\section{CONCLUSION}

To disclose the flow field variation of the water jet inside and outside the nozzle, the author set up a nozzle model by the Fluent software. The simulated results agree well with the theoretical ones, which validate the correctness of the simulation. Then, an experiment was carried out to capture the speed distributions of the water jet at the sections perpendicular to the nozzle axis. The results show that the water jet speed was basically the same at different distances from the axis. To maintain the same speed, the section length grew shorter the farther away from the axis. In addition, the author also discussed the relationship between the flow field inside and outside the nozzle and the nozzle outlet diameter. It is discovered that the water jet speed is positively proportional to nozzle outlet diameter at the same distance from the nozzle axis; the water jet speed is negatively correlated to the axial distance from the nozzle axis across all nozzle outlet diameters. Moreover, the greater the outlet diameter, the more powerful the water jet, and the better the coal cutting effect.

\section{ACKNOWLEDGMENT}

The project is supported by the Joint Funds of Guizhou Provincial Department of Science and Technology, Bijie Municipal Bureau of Science and Technology and Bijie University (Grant No. LH [2017]7016). The project is supported by Guizhou Provincial Science and Technology Fund (Grant No. [2016]1057).

\section{REFERENCES}

[1] Yang W., Lin B.Q., Xu J.T. (2014). Gas outburst affected by original rock stress direction, Natural Hazards, Vol. 72, No. 2, pp. 1063-1074. DOI: 10.1007/s11069-014-1049-z

[2] Sobczyk J. (2014). A comparison of the influence of adsorbed gases on gas stresses leading to coal and gas outburst, Fuel, Vol. 115, No. 2, pp. 288-294. DOI: 10.1016/j.fuel.2013.07.016

[3] Yang W., Lin B.Q., Zhai C., Li X.Z., Sun X., Zhang C. (2012). A new technology for coal and gas control based on the in situ stress distribution and the roadway layout, International Journal of Mining Science and Technology, Vol. 22, No. 2, pp. 145-149. DOI: 10.1016/j.ijmst.2011.08.002

[4] Skoczylas N. (2012). Coal seam methane pressure as a parameter determining the level of the outburst risklaboratory and in situ research, Archives of Mining Sciences, Vol. 57, No. 4, pp. 861-869. DOI: 10.2478/v10267-012-0056-8

[5] Liu J.C., Wang H.T., Yuan Z.G., Fan X.G. (2011). Experimental study of pre-splitting blasting enhancing pre-drainage rate of low permeability heading face, Procedia Engineering, Vol. 26, pp. 818-823. DOI: 10.1016/J.PROENG.2011.11.2242

[6] Lei D.J., Li C.W., Zhang Z.M., Zhang Y.G. (2010). Coal and gas outburst mechanism of the "Three Soft" coal seam in western Henan, Mining Science and Technology, Vol. 20, No. 5, pp. 712-717. DOI: 10.1016/S1674-5264(09)60268-4

[7] Sobczyk J. (2010). The influence of sorption processes on gas stresses leading to the coal and gas outburst in the laboratory conditions, Fuel, Vol. 90, No. 3, pp. 1018-1023. DOI: 10.1016/j.fuel.2010.11.004

[8] Zarrouk S.J., Moore T.A. (2008). Preliminary reservoir model of enhanced coalbed methane (ECBM) in a subbituminous coal seam, Huntly Coalfield, New Zealand, International Journal of Coal Geology, Vol. 77, No. 1, pp. 153-161. DOI: 10.1016/j.coal.2008.08.007

[9] Chen H.D., Cheng Y.P., Ren T.X., Zhou H.X., Liu Q.Q. (2014). Permeability distribution characteristics of 
protected coal seams during unloading of the coal body, International Journal of Rock Mechanics and Mining Sciences, Vol. 71, pp. 105-116. DOI: 10.1016/j.ijrmms.2014.03.018

[10] Min J. (2000). Analysis of the stability of water-jet cutting with linear theory, Journal of Materials Processing Tech, Vol. 104, No. 1-2, pp.17-20. DOI: 10.1016/S0924-0136(00)00583-5

[11] Li Q.G., Lin B.Q., Zhai C. (2015). A new technique for preventing and controlling coal and gas outburst hazard with pulse hydraulic fracturing: A case study in Yuwu coal mine, China, Natural Hazards, Vol. 75, No. 3, pp. 2931-2946. DOI: $10.1007 / \mathrm{s} 11069-014-1469-9$

[12] Zhang J.C., Bian X.B. (2015). Numerical simulation of hydraulic fracturing coalbed methane reservoir with independent fracture grid, Fuel, Vol. 143, No. 10, pp. 543-546. DOI: 10.1016/j.fuel.2014.07.013

[13] Fan T.G., Zhang G.Q., Cui J.B. (2014). The impact of cleats on hydraulic fracture initiation and propagation in coal seams, Petroleum Science, Vol. 11, No. 4, pp. 532-539. DOI: $10.1007 / \mathrm{s} 12182-014-0369-7$
[14] Huang B.X., Li P.F., Ma J., Chen S.L. (2014). Experimental investigation on the basic law of hydraulic fracturing after water pressure control blasting, Rock Mechanics and Rock Engineering, Vol. 47, No. 4, pp. 1321-1334. DOI: 10.1007/s00603-013$\underline{0470-\mathrm{Z}}$

[15] Yi Q.J., Tian M.C., Fang D. (2015). CFD simulation of air-steam condensation on an isothermal vertical plate, International Journal of Heat and Technology, Vol. 33, No. 1, pp. 25-32. DOI: 10.18280/ijht.330104

[16] Tian Y.B., Wang J., Wang L. (2015). Optimal design schemes of centrifugal pump compound impeller at super-low specific speed, Chemical Engineering Transactions, Vol. 46, pp. 811-816. DOI: 10.3303/CET1546136

[17] Yao S.G., Jia X.W., Huang T., Duan L.B. (2015). Numerical simulation of bubble motion in boiling nanofluids based on Lattice Boltzmann method, International Journal of Heat and Technology, Vol. 33, No. 1, pp. 71-76. DOI: $10.18280 /$ ijht.330110 